\title{
A Chemotactic S100 Peptide Enhances Scavenger Receptor and Mac-1 Expression and Cholesteryl Ester Accumulation in Murine Peritoneal Macrophages In Vivo
}

\author{
Wendy Lau, Jannine M. Devery, and Carolyn L. Geczy \\ The Heart Research Institute, Camperdown, New South Wales 2050, Australia
}

\begin{abstract}
In the early development of atherosclerotic plaque, monocytes are recruited to the arterial intima where they accumulate lipid and become foam cells. The recently described murine chemotactic $\mathbf{S 1 0 0}$ protein, CP-10, may have an important role in this process. Intraperitoneal injection of CP$10_{42-55}$ (chemotactic hinge region peptide) into mice caused a sustained leukocyte recruitment with a sixfold increase in

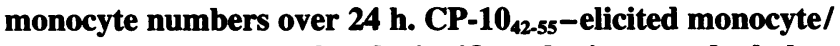
macrophages accumulated significantly increased cholesteryl esters in response to acetylated LDL, both in vivo and in vitro and this was associated with a twofold increase in scavenger receptor expression. By contrast, thioglycollateand macrophage colony-stimulating factor-elicited macrophages expressed levels of scavenger receptor similar to those on resident macrophages and did not exhibit enhanced acetylated LDL loading in vitro. The leukocyte integrin Mac-1 (CD11b/CD18) and its $\beta$ subunit (CD18), but neither lymphocyte function-associated antigen-1 nor very late activation antigen-4, were upregulated on monocyte/macrophages elicited by $\mathrm{CP}-\mathbf{1 0}_{42-55}$, thioglycollate, and macrophage colony-stimulating factor. Cholesteryl ester accumulation in vitro was significantly enhanced by adhesion, which appeared to involve macrophage activation via ligation of Mac-1. The initial events of monocyte recruitment and adhesion to the vessel wall may be important in macrophage foam cell development, and CP-10 or related $\mathrm{S100}$ proteins may contribute to the early inflammatory events of atherogenesis by stimulating these events. (J. Clin. Invest. 1995. 95:1957-1965.) Key words: atherosclerosis • low density lipoprotein - inflammation - chemotactic factors - cell adhesion
\end{abstract}

\section{Introduction}

The pathogenesis of atherosclerosis is a chronic process which develops within a complex inflammatory and hyperlipidemic

This work was presented in part at the Keystone Symposium on Inflammation, Growth Regulatory Molecules, and Atherosclerosis on 1623 January 1994 in Keystone, CO and was published in abstract form (1994. J. Cell. Biochem. Suppl. 18A:270).

Address correspondence to Dr. Carolyn Geczy, The Heart Research Institute, 145 Missenden Road, Camperdown, NSW 2050, Australia. Phone: 61-2-550-3560; FAX: 61-2-550-3302.

Received for publication 1 June 1994 and in revised form 9 January 1995.

J. Clin. Invest.

(c) The American Society for Clinical Investigation, Inc. 0021-9738/95/05/1957/09 \$2.00

Volume 95, May 1995, 1957-1965 environment (1). Although its etiology is unknown, the early recruitment of monocytes to the arterial intima and their subsequent accumulation of modified LDL are well documented (2). Monocyte recruitment is highly regulated and is influenced by a variety of chemotactic factors such as FMLP (3), macrophage colony-stimulating factor (M-CSF), ${ }^{1}$ (4) or monocyte chemoattractant protein-1 (5), and the expression of adhesion molecules (6). Our laboratory described a novel murine chemotactic mediator termed CP-10 (chemotactic protein of molecular mass $10.3 \mathrm{kD}$ ), an $\mathrm{S} 100$ protein with potent chemotactic activity for myeloid cells in vitro $(7,8)$ and in vivo $(8,9)$. S100 proteins are characterized by two highly conserved calcium-binding domains separated by a highly divergent "hinge" region. The hinge region of $\mathrm{CP}-10\left(\mathrm{CP}-10_{42-55}\right)$ contributes significantly to the chemotactic activity of the protein, measured using Boyden chamber assays (8). In contrast to "classical" leukocyte chemotactic agents (FMLP, C5a, IL-8), which elicit relatively weak and transient $(2-6 \mathrm{~h})$ inflammatory reactions in vivo (10, 11), CP-10 elicits a more sustained (4-24 h) inflammatory response $(8,9)$.

Adhesion molecules on both leukocytes and endothelial cells are important in mediating leukocyte attachment and accumulation at inflammatory foci. The leukocyte $\beta_{1}$ and $\beta_{2}$ integrins play a critical role in mediating strong, sustained adhesion (6) and their engagement may influence leukocyte activation and effector functions $(12,13)$. Mac-1 (CD11b/CD18, $\left.\alpha_{M} \beta_{2}\right)$ and lymphocyte function-associated antigen-1 (LFA-1, CD11a/ $\mathrm{CD} 18, \alpha_{\mathrm{L}} \beta_{2}$ ) share a common $\beta$ chain (CD18) whereas very late activation antigen-4 (VLA-4, CD49d/CD29, $\alpha_{4} \beta_{1}$ ) belongs to the $\beta 1$ family. Mac- 1 recognizes a diverse array of ligands involved in the inflammatory process. These include complement protein fragment $\mathbf{C} 3$ bi, fibrinogen, factor $\mathbf{X}$, and denatured proteins $(13,14)$. The endothelial cell counterreceptors for Mac-1 and LFA-1 (intercellular adhesion molecule-1 [ICAM1]) and for VLA-4 (vascular cell adhesion molecule-1 [VCAM1]) are reportedly expressed in human atherosclerotic plaque $(15,16)$.

Macrophages in the subendothelial space accumulate cholesteryl esters (CEs) to become foam cells $(1,2)$. The scavenger receptor (SR) mediates uptake of modified LDL such as oxidized LDL and acetylated LDL (AcLDL) (17) and may be involved in macrophage foam cell formation in vivo (18). It may also mediate other potentially important physiological functions including binding of LPS (19) and adhesion (20). Unlike the LDL receptor it is not downregulated in response to

1. Abbreviations used in this paper: AcLDL, acetylated LDL; CE, cholesteryl ester; i.p., intraperitoneal; LFA-1, lymphocyte function-associated antigen-1; M-CSF, macrophage colony-stimulating factor; MRP-8, migration inhibitory factor-related protein-8; SR, scavenger receptor; TG, thioglycollate; VLA-4, very late activation antigen-4. 
high levels of intracellular cholesterol (21). SR mRNA expression in macrophages in human atherosclerotic lesions is not uniform (18), and its activity may be dependent on macrophage maturation $(22,23)$. Functional expression is increased by $\mathbf{M}$ $\operatorname{CSF}(24,25)$ whereas $\operatorname{TGF} \beta 1(26), \operatorname{IFN} \gamma(27,28)$, and TNF $\alpha$ (29) decrease activity. Little is known concerning SR expression or activity on monocyte/macrophages recruited in vivo.

In this report we compared monocyte/macrophages elicited intraperitoneally (i.p.) in mice by CP-10 $0_{42-55}$ with those recruited by other proinflammatory chemotactic agents: M-CSF (which is present in atherosclerotic plaque [30]), thioglycollate (TG), and FMLP. In contrast to M-CSF, TG, and FMLP, CP-10 elicited monocyte/macrophages accumulated significantly increased CEs in response to AcLDL both in vivo and in vitro and expressed increased levels of SR. Expression of Mac-1 and its $\beta$ subunit CD18 was upregulated on monocyte/macrophages elicited by CP-10 ${ }_{42-55}, \mathrm{M}-\mathrm{CSF}$, and TG, whereas LFA-1 and VLA-4 levels were similar to those of the resident population. Macrophage AcLDL loading was significantly enhanced by adhesion, possibly via activation of Mac-1. These findings suggest a potential pathogenic role for $\mathrm{CP}-10$ or related $\mathrm{S} 100$ proteins in stimulating monocyte recruitment and foam cell formation.

\section{Methods}

\section{Reagents}

Lyophilized CP-10 $42-55$ (PQFVQNINIENLFR) as described (8) was dissolved in $50 \mu \mathrm{l}$ of $70 \%$ formic acid, resuspended in $0.1 \%$ (wt/vol) low endotoxin BSA (Sigma Immunochemicals, St. Louis, MO) in normal saline, and $\mathrm{pH}$ adjusted to 6.5 using $1 \mathrm{M}$ sodium hydroxide. FMLP (Sigma Immunochemicals) was stored as a concentrated stock solution $\left(10^{-3} \mathrm{M}\right)$ in DMSO at $-20^{\circ} \mathrm{C}$. Recombinant human M-CSF (sp act 2 $\times 10^{8} \mathrm{U} / \mathrm{mg}$ protein; active in mouse [31]) was a gift from Chiron Corp. (Emeryville, CA). TG medium, Brewer modified, was from BBL Microbiology Systems (Cockeysville, MD). DME with $4.5 \mathrm{~g} /$ liter glucose and 1-glutamine (hereafter referred to as DME) and HBSS were from Cytosystems (New South Wales, Australia). Monoclonal antibody 2 F8 to murine macrophage SR was prepared by I. P. Fraser and D. Hughes (Oxford, United Kingdom) (20); mAb M1/70 against Mac-1 antigen (CD11b/CD18) was from Boehringer Mannheim GmbH (Mannheim, Germany); anti-mouse CD18 mAb (clone C71/16) and anti-mouse granulocyte $\mathrm{mAb}$ (clone RB6-8C5) were from PharMingen (San Diego, CA); and anti-mouse F4/80 antigen (clone C1:A3-1) was from Serotec Ltd. (Oxford, United Kingdom). The isotype control for these $\mathbf{m A b s}$ was rat $\mathrm{IgG}_{2 \mathrm{~b}}$ myeloma protein from ICN ImmunoBiologicals (Costa Mesa, CA). mAbs to mouse LFA-1 (CD11a/CD18; clone M17/4.4.11.9) and VLA-4 (CD49d/CD29; clone R1-2) were produced from rat hybridomas TIB 217 and HB 227 (American Type Culture Collection, Rockville, MD), respectively; hybridoma supernatant of rat IgG was used as control. $F\left(a b^{\prime}\right)_{2}$ goat anti-rat Ig-R-phycoerythrin was from Southern Biotechnology Associates Inc. (Birmingham, AL).

\section{Animals and peritoneal cell harvest}

BALB/c mice aged 8-10 wk and housed under conventional hygienic conditions received i.p. injections of $1 \mathrm{ml}$ of $2.5 \mu \mathrm{M} \mathrm{CP}-10_{42-55}$ in $0.025 \%$ (wt/vol) low endotoxin BSA/normal saline, or equivalent concentration of diluent. The optimum concentration of $\mathrm{CP}-10_{42-5 s}$ for cell recruitment was predetermined using injections of 0.05-5 $\mu \mathrm{M} \mathrm{CP}$ $10_{42-55}(9)$. In some experiments FMLP ( 1 and $10 \mu \mathrm{M}, 1 \mathrm{ml}$ ), M-CSF $(2 \mu \mathrm{g}, 1 \mathrm{ml})$, or TG $(1.5 \mathrm{ml})$ was injected in an attempt to compare the response elicited by $\mathrm{CP}-10_{42-55}$ with other proinflammatory agents. Cells were harvested by peritoneal lavage using 6-8 ml cold HBSS or DME containing $0.38 \%$ (wt/vol) trisodium citrate, $100 \mathrm{U} / \mathrm{ml}$ penicillin, and $100 \mu \mathrm{g} / \mathrm{ml}$ streptomycin. Viability of washed cell suspensions was $>98 \%$ as determined by Trypan blue exclusion. Differential staining was performed using a modified Wright-Giemsa stain (Diff-Quik Set; Lab-Aids, New South Wales, Australia). Endotoxin content of reagents used for cell harvest and culture was $<60 \mathrm{pg} / \mathrm{ml}$ at the concentrations used and was determined with a chromogenic limulus amoebocyte lysate assay (Associates of Cape Cod, Inc., Woods Hole, MA).

\section{LDL preparation and macrophage lipid loading}

Human LDL was isolated from the serum of healthy, normolipidemic, fasting donors by sequential ultracentrifugation as described (32) and used within $7 \mathrm{~d}$. AcLDL was prepared according to the method of Basu et al. (33), except $6 \mu$ lacetic anhydride/mg LDL protein was used for acetylation. Copper-mediated LDL oxidation was achieved as described (32). The protein content of LDL samples and cell lysates was determined by the bicinchoninic assay (Sigma Immunochemicals) using BSA (fraction V; Sigma Immunochemicals) as standard.

In vivo lipid loading experiments. Mice received i.p. injections of CP-10 $42-55$, FMLP, or diluent as described. AcLDL ( $250 \mu \mathrm{g}$ protein, 1 $\mathrm{ml}$ ) or normal saline was injected after $8 \mathrm{~h}$ and cells harvested $24 \mathrm{~h}$ later, or at 8 and $24 \mathrm{~h}$ after CP-10 ${ }_{42-55}$ injection and cells harvested 48 h later. Two sequential injections of AcLDL were used for the 48-h samples to allow for rapid clearance from the peritoneal cavity.

In vitro lipid loading experiments. Peritoneal cells from 3-6 mice per group were pooled, and $4 \times 10^{6}$ cells were plated in $22.6-\mathrm{mm}-$ diameter polystyrene tissue culture wells (Costar Corp., Cambridge, MA) in $2 \mathrm{ml}$ of DME containing 10\% (vol/vol) human lipoproteindeficient serum, $100 \mathrm{U} / \mathrm{ml}$ penicillin, and $100 \mu \mathrm{g} / \mathrm{ml}$ streptomycin, with or without AcLDL ( $50 \mu \mathrm{g}$ protein $/ \mathrm{ml}$ ), and incubated at $37^{\circ} \mathrm{C}$ in humidified $5 \% \mathrm{CO}_{2}$ for $24 \mathrm{~h}$. TG-elicited cells were harvested 16 or $72 \mathrm{~h}$ after injection. Although the composition of the elicited cell populations varied, AcLDL available for macrophages was not limiting because predetermined saturating levels were used. In preliminary experiments, cells were incubated with oxidized LDL ( $50 \mu \mathrm{g}$ protein $/ \mathrm{ml}$ ) for $24 \mathrm{~h}$. Viability of cells cultured in adherent conditions was $>94 \%$. Nonadherent culture was performed in Nunc Minisorp polypropylene tubes (Nunc, Roskilde, Denmark), and cell viability was $\geq 93 \%$ at the end of the incubation period. In experiments using anti-Mac-1, cells were preincubated in nonadherent conditions with $1 \mu \mathrm{g} / \mathrm{ml}$ anti-Mac-1 (clone M1/ 70) or isotype control (rat $\mathrm{IgG}_{2 b}$ ) for $30 \mathrm{~min}$ at $37^{\circ} \mathrm{C}$ before adding AcLDL.

\section{Analysis of intracellular lipid}

HPLC. Cells were washed 3 times with cold PBS, lysed with $0.6 \mathrm{ml}$ of $0.2 \mathrm{M} \mathrm{NaOH}$ and intracellular lipid extracted from 0.3 to $0.4 \mathrm{ml}$ of lysate analyzed for cholesterol, CEs, or lipid oxidation products by HPLC as described (32).

Oil red $O$ staining. Cell suspensions were cytocentrifuged onto glass slides and stained with oil red $O$ (34). Alternatively, cells cultured on sterile glass coverslips in tissue culture wells under the experimental conditions specified were washed twice with cold PBS before fixing and staining. Counterstain was Gill's hematoxylin (Sigma Immunochemicals).

\section{Flow cytometry}

Resident or elicited peritoneal cells $\left(10^{6}\right.$ cells $)$ were suspended in $20 \%$ heat-inactivated normal mouse serum/phenol red-free HBSS to block nonspecific binding, then incubated with the primary or isotype-matched control antibody in phenol red-free HBSS/5\% heat-inactivated normal mouse serum $/ 0.05 \%$ sodium azide for $60 \mathrm{~min}$ at $4^{\circ} \mathrm{C}$. Saturating concentrations of primary antibodies were used and hybridoma supernatants were undiluted. Cells were washed twice, incubated with $\mathrm{F}\left(\mathrm{ab}^{\prime}\right)_{2}$ goat anti-rat Ig-R-phycoerythrin for $30 \mathrm{~min}$ at $4^{\circ} \mathrm{C}$, and after a final wash were fixed with $1 \%$ paraformaldehyde/PBS and analyzed by flow cytometry using the EPICs Profile II system (Coulter Corp., Hialeah, FL). Fluorescence data were collected from 5,000 cells within the bit map gates. Net fluorescence was the mean channel fluorescence of cells stained with the mAb minus that of cells stained with isotype control antibody. 
Table I. Characterization of Inflammatory Infiltrate Elicited by i.p. Injections of CP-10 $42-55$

\begin{tabular}{|c|c|c|c|c|c|c|c|}
\hline \multirow[b]{2}{*}{ Time } & \multicolumn{3}{|c|}{ Total cells per mouse } & \multicolumn{2}{|c|}{ Percentage of neutrophils } & \multicolumn{2}{|c|}{ Percentage of macrophages } \\
\hline & Diluent $\left(\times 10^{6}\right)$ & CP-10 $10_{42-55}\left(\times 10^{6}\right)$ & Stimulation index & Diluent & CP-10 ${ }_{42-55}$ & Diluent & CP-10 ${ }_{42-55}$ \\
\hline \multicolumn{8}{|l|}{$h$} \\
\hline 0 & $3.1 \pm 0.3$ & & 1 & $0.4 \pm 0.2$ & & $66.6 \pm 1.5$ & \\
\hline 8 & $2.4 \pm 0.5$ & $4.9 \pm 1.0 *$ & $2.2 \pm 0.3^{\ddagger}$ & $33.8 \pm 3.1$ & $59.7 \pm 1.9^{8}$ & $53.2 \pm 5.6$ & $26.1 \pm 1.4^{8}$ \\
\hline 24 & $6.6 \pm 1.1$ & $16.6 \pm 3.7^{\ddagger}$ & $2.4 \pm 0.3^{\ddagger}$ & $19.2 \pm 2.9$ & $35.3 \pm 3.3^{8}$ & $59.0 \pm 2.0$ & $44.1 \pm 3.1^{8}$ \\
\hline 48 & $8.0 \pm 1.0$ & $10.4 \pm 1.6$ & $1.1 \pm 0.3$ & $2.8 \pm 0.7$ & $4.4 \pm 0.7$ & $72.4 \pm 3.0$ & $69.2 \pm 2.9$ \\
\hline
\end{tabular}

Mice received $1 \mathrm{ml}$ i.p. injections consisting of CP-10 ${ }_{42-55}$ or diluent, cells were harvested after 8,24 , and $48 \mathrm{~h}$ and counted, and leukocytes were quantitated by differential staining. Each value represents the mean \pm SEM of cells from at least 10 mice. The total number of cells elicited per mouse was calculated as a stimulation index (CP-10 ${ }_{42-55}$-elicited cells/control diluent-elicited cells) to allow for day-to-day and batch-to-batch variations in the mice. ${ }^{*} P<0.05,{ }^{\ddagger} P<0.01,{ }^{\sharp} P<0.001$ versus controls.

\section{Statistical analysis}

Data were analyzed using Student's $t$ test, except for analysis of stimulation indices (Table I), which was performed using Wilcoxon signed ranks test for non-parametric data.

\section{Results}

Inflammatory infiltrate elicited by $\mathrm{CP}-10_{42-55}$. Intraperitoneal injection of $\mathrm{CP}-10_{42-55}$ elicited a sustained recruitment of cells over 8-24 h (Table I). Total cell numbers increased significantly, by more than twofold compared with controls at 8 and $24 \mathrm{~h}$ (stimulation indices 2.2 and 2.4 , respectively), returning to near-control values by $48 \mathrm{~h}$ (stimulation index 1.1). The acute inflammatory infiltrate $(8 \mathrm{~h})$ consisted predominantly of neutrophils (60\%). By $24 \mathrm{~h}$ the proportion of monocyte/macrophages significantly increased (from $26 \%$ at $8 \mathrm{~h}$ to $44 \%$ at 24 h). The absolute number of monocyte/macrophages increased from $1.2 \times 10^{6}$ at $8 \mathrm{~h}$ to $7.3 \times 10^{6}$ per mouse at $24 \mathrm{~h}$, then remained unchanged between 24 and $48 \mathrm{~h}\left(7.3 \times 10^{6}\right.$ at $\left.48 \mathrm{~h}\right)$, indicating that monocyte recruitment occurred mainly between 8 and $24 \mathrm{~h}$ after CP-10 $0_{42-55}$ injection.

Macrophage lipid accumulation in vivo. Fig. $1 A$ shows $\mathrm{CE}$ and free cholesterol accumulation in mouse peritoneal cells harvested 24 or $48 \mathrm{~h}$ after the initial injection of CP-10 $10_{42-55}$ or diluent followed by AcLDL or saline. Total cell protein was proportional to the number of cells harvested and ranged from $116 \pm 12 \mu \mathrm{g}$ for control cells harvested after $24 \mathrm{~h}$ to $204 \pm 30 \mu \mathrm{g}$ for cells from mice injected with CP-10 $0_{42-55}$ and AcLDL and harvested after $48 \mathrm{~h}$. The proportion of macrophages did not vary significantly between different groups within the same time point, thus the contribution to total cell protein from cells other than macrophages was not significantly different in any group within each time point.

Intraperitoneal injection of AcLDL caused macrophage CE accumulation which became significant only after $48 \mathrm{~h}$ ( $P$ $=0.002$ compared with control mice). When AcLDL was preceded by $\mathrm{CP}-10_{42-55}$, macrophage $\mathrm{CE}$ accumulation markedly increased. This was 2.4 times that of cells from control mice injected with diluent and AcLDL only $(P=0.01)$ after $48 \mathrm{~h}$, and 3.7 times that of corresponding cells harvested after $24 \mathrm{~h}$ $(P=0.01)$. The CE fraction of the total cholesterol increased from $28 \pm 2.6 \%$ in cells from AcLDL-injected mice to $38 \pm 3.3 \%$ in cells from mice injected with both CP-10 $10_{42-55}$ and AcLDL after $24 \mathrm{~h}(P=0.04)$, and from $47 \pm 4.7$ to $59 \pm 2.8 \%$ in corresponding groups harvested after $48 \mathrm{~h}(P=0.08)$. Changes in free cholesterol followed a similar pattern, but were less marked than changes in CE content. Comparable amounts of native LDL did not accumulate as $\mathrm{CE}$ either in resident or $\mathrm{CP}$ $10_{42-55}$-elicited macrophages (not shown).

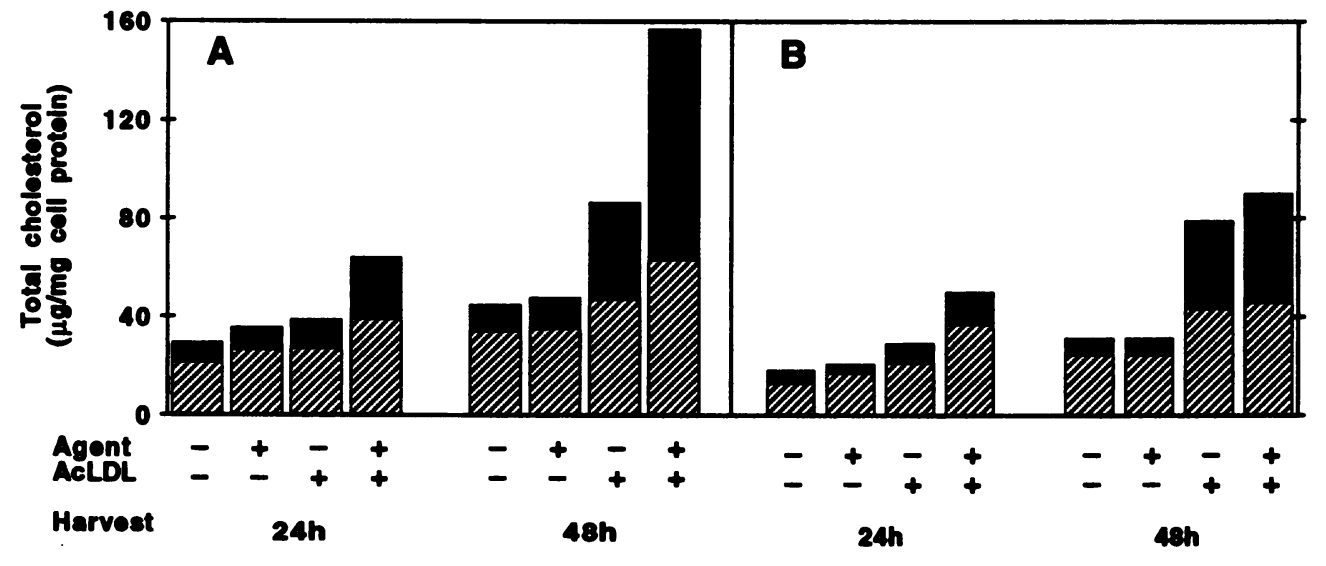

Figure 1. Free (hatched bars) and esterified (filled bars) cholesterol accumulation in $\mathrm{CP}-10_{42-55}-(2.5$ $\mu \mathrm{M}, \boldsymbol{A})$ and FMLP-elicited (10 $\mu \mathrm{M}, B$ ) peritoneal cells in response to AcLDL in vivo. Mice received i.p. injections of the chemotactic agent or diluent $(+$ or - , top row), followed by AcLDL or saline (+ or -, bottom row) as described in Methods. Peritoneal cells were harvested 24 or $48 \mathrm{~h}$ after the initial injection, and intracellular lipid extracted and analyzed by HPLC. Each column represents the mean of at least six mice. Values for SEMs fall within $20 \%$ of mean values for each sample. 


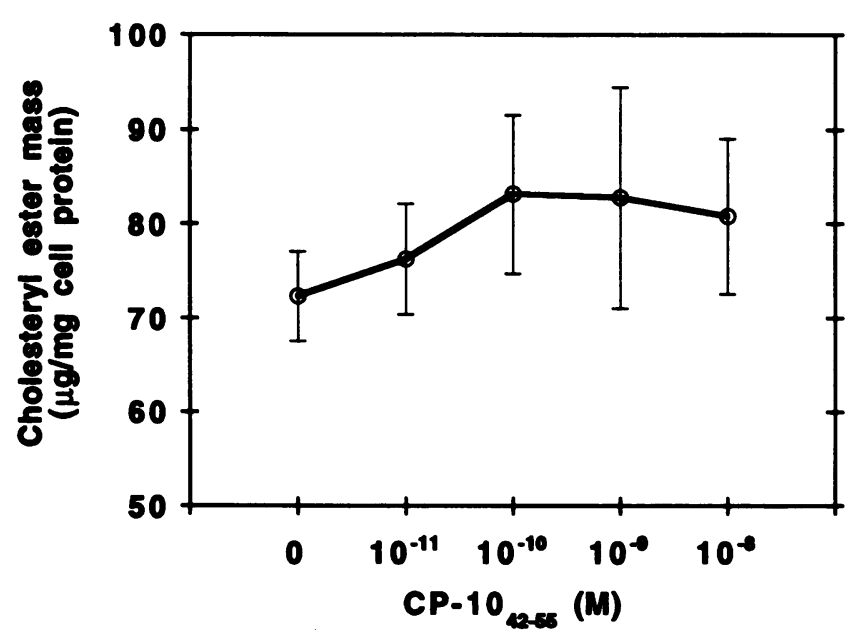

Figure 2. The effect of CP-10 $0_{42-55}$ on CE accumulation in resident peritoneal macrophages. Resident peritoneal cells were incubated for $24 \mathrm{~h}$ with AcLDL ( $50 \mu \mathrm{g}$ protein $/ \mathrm{ml}$ ) and the concentrations of CP-10 $0_{42-55}$ given, and lipid extracted and analyzed as described in Methods. Data represent the means \pm SEM of six incubations involving two separate experiments.

In comparison to CP-10 $10_{42-55}$, i.p. injections of FMLP ( 1 and $10 \mu \mathrm{M}$ ) elicited weak responses; total cell recruitment was $1.2 \pm 0.7$ times $(n=9)$ that of control mice after $8 \mathrm{~h}(\mathrm{NS})$, but PMN and macrophage numbers were the same as diluent-elicited cells after $24 \mathrm{~h}$. Although oil red $\mathrm{O}$ staining indicated increased lipid accumulation in FMLP-elicited macrophages ( 24 and $48 \mathrm{~h}$ ) from mice injected with AcLDL (not shown), CE levels determined by HPLC were less than those in CP$10_{42-55}$-elicited cells and the differences failed to reach significance (Fig. $1 \mathrm{~B}$ ).

Macrophage lipid accumulation in vitro. Resident cells cultured with CP-10 ${ }_{42-55}$ and AcLDL had only minor, statistically insignificant increased $\mathrm{CE}$ accumulation (Fig. 2). In contrast, monocyte/macrophages elicited by $\mathrm{CP}-10_{42-55}$ accumulated markedly increased CEs compared with control (diluent-elicited) cells when cultured with AcLDL in vitro (Fig. $3 A$ ). Cells cultured without AcLDL contained predominantly free cholesterol with only low levels of CEs. Control cells cultured with AcLDL contained significant levels of CE, whereas 24-h CP-10 ${ }_{42-55}$-elicited macrophages had even more CE (1.7-fold, $P=0.005)$. CE accumulation in both control and 24-h CP$10_{42-55}$-elicited macrophages was completely inhibited by fucoidin ( $50 \mu \mathrm{g} / \mathrm{ml}$, not shown ), consistent with SR involvement in AcLDL uptake. The CE fraction of total cholesterol of diluent- or CP-10 $10_{42-55}$-elicited macrophages cultured with AcLDL increased from $55 \pm 5.8$ to $70 \pm 4.5 \%(P=0.02)$ and from $59 \pm 4.4$ to $78 \pm 0.8 \%(P=0.009)$ in macrophages harvested at 8 and 24 h, respectively. In contrast, no significant differences in either total cholesterol (from $85.8 \pm 5.0$ to $90.4 \pm 5.3 \mu \mathrm{g} / \mathrm{mg}$ protein) or CE fraction (from $56 \pm 3.0$ to $60 \pm 3.3 \%$ ) were evident in macrophages harvested after $48 \mathrm{~h}$.

A single i.p. injection of M-CSF $(2 \mu \mathrm{g})$ elicited a weak response at $24 \mathrm{~h}$ (stimulation index 1.3 \pm 0.3 ) and comprised predominantly macrophages ( $8 \pm 1 \%$ PMNs, $65 \pm 2 \%$ macrophages). To obtain an inflammatory population containing similar proportions of cell types to that $24 \mathrm{~h}$ after $\mathrm{CP}-10_{42-55}$ injection, cells were harvested $16 \mathrm{~h}$ after TG injection (stimulation

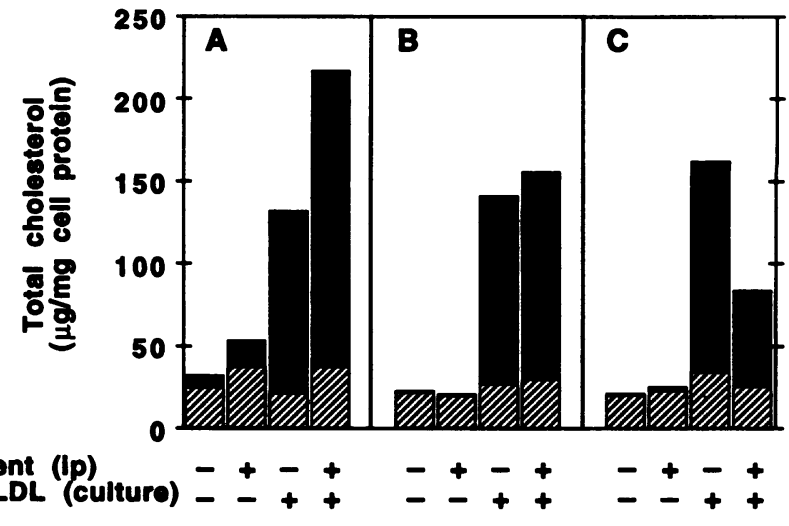

Figure 3. Free (hatched bars) and esterified (filled bars) cholesterol accumulation in CP-10 $0_{42-55}-(A), \mathrm{M}-\mathrm{CSF}-(B)$, and TG-elicited $(C)$ macrophages after $24 \mathrm{~h}$ of incubation with AcLDL in vitro. Peritoneal cells were harvested $24(A, B)$ or $16 \mathrm{~h}(C)$ after i.p. injection of the agent or diluent ( + or - , top row), incubated in the presence or absence of AcLDL ( + or -, bottom row), then lipid extracted from the adherent macrophage population for analysis. Data represent the means of triplicate incubations and are representative of two experiments. Values for SEMs fall within $16 \%$ of mean values for each sample.

index $8.4 \pm 2.3,40 \pm 6 \%$ PMNs, $43 \pm 7 \%$ macrophages ). CE accumulation did not increase significantly in M-CSF-elicited macrophages cultured with AcLDL (Fig. $3 B$ ), whereas 16-h TG-elicited macrophages accumulated substantially less CE ( $P$ $<0.001$ ) than control cells (Fig. $3 C$ ). Cells harvested $72 \mathrm{~h}$ after TG injection ( $80 \pm 2 \%$ macrophages) also loaded less AcLDL (not shown).

Macrophages elicited $24 \mathrm{~h}$ after CP-10 $0_{42-55}$ injection and incubated with oxidized LDL accumulated increased free and esterified cholesterol compared with diluent-elicited controls (not shown). 7-Ketocholesterol, the predominant oxysterol in oxidized LDL, increased 1.5-fold from $7.1 \pm 0.9 \mu \mathrm{g} / \mathrm{mg}$ protein in diluent-elicited cells to $10.7 \pm 1.1 \mu \mathrm{g} / \mathrm{mg}$ protein in $\mathrm{CP}$ $10_{42-55}$-elicited cells. CE content ( $19 \pm 3.8 \%$ of total cholesterol) in $\mathrm{CP}-10_{42-55}$-elicited oxidized LDL-loaded macrophages was $\sim 51 \%$ less than that of AcLDL-loaded macrophages. This was consistent with published observations of the lower CE content in oxidized LDL (32) and oxidized LDL-loaded macrophages (35).

Oil red $O$ staining. Oil red $\mathrm{O}$ staining confirmed the differences in AcLDL loading observed with HPLC analysis, for macrophages loaded in vivo (Fig. $4, A-C$ ) and in vitro (Fig. $4, D-F)$. Macrophages from mice injected with saline and AcLDL only (Fig. $4 B$ ), and from mice injected with both CP$10_{42-55}$ and AcLDL (Fig. $4 C$ ), appeared larger than those from control mice (Fig. $4 \mathrm{~A}$ ). Although lipid staining within macrophages was heterogeneous, there was a marked increase in both the number of cells containing lipid and the lipid content of each cell in CP-10 ${ }_{42-55}$-elicited populations loaded with AcLDL both in vivo and in vitro, compared with diluent-elicited controls.

Analysis of cellular CE composition. Table II shows that the proportions of individual CEs in CP-10 ${ }_{42-55}$-elicited macrophages were similar whether AcLDL loading occurred in vivo or in vitro and did not vary significantly between cells harvested at different times. The major components in both groups were cholesteryl linoleate and cholesteryl oleate, which comprised 

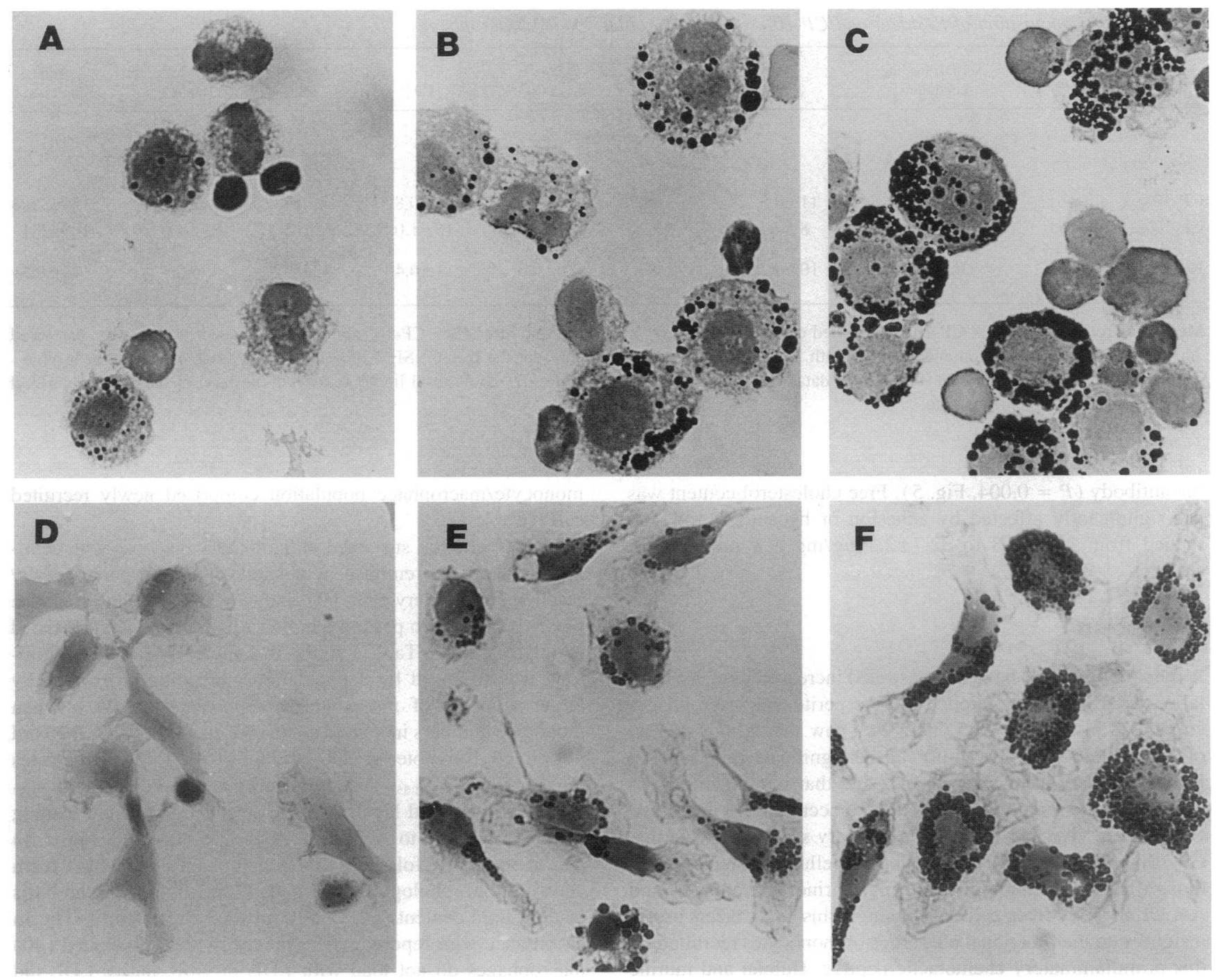

Figure 4. Photomicrographs of mouse peritoneal cells stained with oil red $\mathrm{O}$. In vivo lipid loading $48 \mathrm{~h}$ after i.p. injections of diluent and saline $(A)$, diluent and AcLDL $(B)$, and CP-10 ${ }_{42-55}$ and AcLDL $(C)$. In vitro loading in control diluent-elicited $(D$ and $E)$ and 24-h CP-10 42-55-elicited $(F)$ macrophages, after $24 \mathrm{~h}$ of incubation without $(D)$ or with $(E$ and $F)$ AcLDL. $\times 75$.

$\sim 40$ and $30 \%$ of the total CE fraction, respectively. Loaded resident peritoneal macrophages had proportionally more cholesteryl linoleate $(49 \%)$ and less cholesteryl oleate $(26 \%)$ and cholesteryl palmitate $(11 \%)$.than $\mathrm{CP}-10_{42-55}$-elicited cells. The proportions of individual CEs did not vary significantly between adherent and nonadherent culture conditions (data not shown).

Flow cytometric analysis of scavenger receptor and $\beta$ integrin expression on resident and elicited macrophages. Subpopulations within newly recruited myeloid cell populations were identified using mAbs against Mac-1 (3), F4/80 (36), and mouse granulocyte-specific antigen (37). Activated PMNs were mostly RB6-8C $5^{\text {bright }}$ and Mac- ${ }^{\text {bright }}$, activated monocyte/macrophages were predominantly $\mathrm{F} 4 / 80^{\mathrm{dim}}$ and $\mathrm{Mac}-1^{\text {bright }}$, and resident peritoneal macrophages were $\mathrm{F} 4 / 80^{\text {bright }}$ and Mac- $1^{\text {bright }}$ (not shown). Parallel increases in Mac-1 and CD18 expression were evident on monocyte/macrophages elicited by CP-10 ${ }_{42-55}$, TG and M-CSF, whereas LFA-1 and VLA-4 did not change significantly (Table III). There was an approximately twofold increase in SR expression on CP-10 ${ }_{42-55}$-elicited macrophages after 24 and $48 \mathrm{~h}$, whereas TG- or M-CSF-elicited cells were no different from resident or diluent-elicited cells (Table III).

Effect of adhesion on macrophage lipid accumulation. Macrophage $\mathrm{CE}$ accumulation was profoundly affected by adhesion. CP-10 $42-55$-elicited macrophages incubated with AcLDL for 24 $h$ in adherent conditions had significantly more CE (1.6- to 2fold, $P<0.001$ ) than cells cultured in nonadherent conditions (Fig. 5). Even though resident and TG-elicited macrophages accumulated proportionally less $\mathrm{CE}$ than $\mathrm{CP}-10_{42-55}$-elicited macrophages, adherent culture also significantly increased $\mathrm{CE}$ levels by approximately twofold in these cells (not shown).

To investigate the role of Mac-1 binding in macrophage lipid accumulation and in the absence of a neutralizing antibody to murine Mac-1, we used an anti-Mac-1 mAb (M1/70) which binds to the $\alpha$ subunit (CD1 1b) and induces phenotypic changes which correlate with activation of resident mouse peritoneal macrophages (38). Cells elicited by CP-10 ${ }_{42-55}$ after $24 \mathrm{~h}$ and preincubated with M1/70 in nonadherent conditions before adding AcLDL accumulated increased CEs to a similar degree (1.5fold, $P=0.005$ ) as when adherent cells were cultured without 
Table II. CE Composition of Resident and CP-10 ${ }_{42-55}$-elicited AcLDL-loaded Macrophages

\begin{tabular}{|c|c|c|c|c|c|c|c|c|}
\hline Macrophage type & $\begin{array}{l}\text { AcLDL loading } \\
\text { conditions }\end{array}$ & $\mathrm{CA}$ & $\mathrm{CL}$ & $\mathrm{CO}$ & CP & CS & Total CE & $\begin{array}{c}\text { Total } \\
\text { cholesterol }\end{array}$ \\
\hline & & \multicolumn{5}{|c|}{ percentage of total CE fraction } & \multicolumn{2}{|c|}{$\mu g / m g$ cell protein } \\
\hline CP-10 $42-55$-elicited & In Vivo & $11 \pm 0.3$ & $41 \pm 0.6$ & $29 \pm 0.7$ & $15 \pm 0.8$ & $4 \pm 0.3$ & $94 \pm 17.3$ & $159 \pm 26.4$ \\
\hline CP-10 $42-55$-elicited & In Vitro & $8 \pm 0.4$ & $39 \pm 1.2$ & $31 \pm 0.6$ & $16 \pm 1.0$ & $6 \pm 0.5$ & $80 \pm 4.6$ & $109 \pm 5.1$ \\
\hline Resident & In Vitro & $10 \pm 0.2$ & $49 \pm 0.2$ & $26 \pm 0.3$ & $11 \pm 0.4$ & $4 \pm 0.4$ & $39 \pm 0.4$ & $74 \pm 0.8$ \\
\hline
\end{tabular}

Method as for Figs. 1 and 3. CP-10 $0_{42-55}$-elicited cells loaded in vivo were harvested after $48 \mathrm{~h}$. CP-10-elicited cells loaded in vitro were harvested $24 \mathrm{~h}$ after CP-10 $10_{42-55}$ injection and cultured with AcLDL for $24 \mathrm{~h}$. Results represent the means \pm SEM of cells from at least six mice (for in vivo data) or at least four incubations (for in vitro data). $C A$, cholesteryl arachidonate; $C L$, cholesteryl linoleate; $C O$, cholesteryl oleate; $C P$, cholesteryl palmitate; CS, cholesteryl stearate.

the antibody ( $P=0.004$, Fig. 5). Free cholesterol content was not significantly affected by adhesion or by anti-Mac-1 and ranged from $29.8 \pm 3.8$ to $32.7 \pm 2.4 \mu \mathrm{g} / \mathrm{mg}$ cell protein (not shown).

\section{Discussion}

A number of studies have demonstrated increased lipid accumulation by resident and elicited murine peritoneal macrophages stimulated in vitro $(17,25,39)$. We show that administration of AcLDL alone in vivo (i.p.) caused significant lipid loading in resident peritoneal macrophages and that monocyte/macrophages newly recruited by $\mathrm{CP}-10_{42-55}$ accumulated increased CEs both in vivo and in vitro. Preliminary studies indicate that $\mathrm{CP}-10_{1-88}$ (full length) elicits similar cellular responses. Although there are limitations in using murine macrophages and AcLDL to study foam cell development, this study offers useful insights into the functional properties of monocytes recruited by this proinflammatory chemotactic peptide. Human and murine monocyte/macrophages display similarities in that both types express SRs $(17,22)$, and lipid loading in vitro may be modulated by various cytokines $(24,26,28,29)$. Human peripheral blood-derived monocytes differentiated in vitro $(22,23)$, macrophage cell lines (26), and murine resident peritoneal (17), TG-elicited $(39,40)$, or macrophages elicited by various other nonphysiological inflammatory agents $(25,39)$ have been used to investigate lipid accumulation. However, lipid loading characteristics of these macrophage subtypes may be functionally different from newly recruited cells. We examined responses of cells recruited over 8 to $48 \mathrm{~h}$ when a large proportion of the monocyte/macrophage population comprised newly recruited cells (Table I).

CP-10 elicits a sustained inflammatory response with cellular characteristics reminiscent of a delayed-type hypersensitivity reaction (8). Devery et al. (9) characterized the acute response to $\mathrm{CP}-10_{42-55}$ which peaked $8 \mathrm{~h}$ after i.p. injection and consisted mainly of PMNs. Table I shows that the early PMN-rich infiltrate was followed by a population containing proportionally larger numbers of monocyte/macrophages after $24 \mathrm{~h}$ when monocyte numbers increased some sixfold. Although CP-10 did not directly promote AcLDL loading of resident macrophages (Fig. 2), CP-10 ${ }_{42-55}$-elicited macrophages accumulated significantly increased levels of CEs, a reflection of lipid loading (41), in response to AcLDL both in vivo (2.4-fold; Fig. $1 A$ ) and in vitro (1.7-fold; Fig. 3). Macrophages resembled foam cells both morphologically (Fig. 4, $C$ and $F$ ) and on the basis of their lipid content ( $C E>50 \%$ of total cholesterol [41]). In accordance with reports that resident (17) or TG-elicited (40) macrophages do not load with LDL in vitro, native LDL did not accumulate as $\mathrm{CE}$ either in resident or $\mathrm{CP}-\mathbf{1 0}_{42-55}$-elicited macrophages. FMLP was used in an attempt to compare the responses provoked by $\mathrm{CP}-10_{42-55}$ with a classical chemoattractant. This agent failed to recruit significant numbers of monocyte/macrophages and only minor increases in lipid loading were evident in vivo (Fig. $1 \mathrm{~B}$ ). The cell population elicited $16 \mathrm{~h}$ after TG injection had a similar composition to that elicited by $\mathrm{CP}-10_{42-55}$ after $24 \mathrm{~h}$ but AcLDL loading in vitro was decreased compared with resident cells (Fig. $3 C$ ). These results suggest that the increased $\mathrm{CE}$ accumulation in response to AcLDL observed with CP-10 $0_{42-55}$-elicited macrophages was not

Table III. Expression of Scavenger Receptor and $\beta$ Integrins on Resident and Elicited Monocyte/Macrophages

\begin{tabular}{|c|c|c|c|c|c|}
\hline & Resident & TG $16 \mathrm{~h}$ & CP-10 $10_{42-55} 24 \mathrm{~h}$ & M-CSF 24 h & CP-10 $42-5548 \mathrm{~h}$ \\
\hline SR & $13.0 \pm 1.1$ & $11.1 \pm 1.3$ & $27.9 \pm 3.1^{8}$ & $11.5 \pm 1.4$ & $25.8 \pm 3.9^{\ddagger}$ \\
\hline Mac-1 & $63.9 \pm 5.8$ & $162.9 \pm 24.8^{8}$ & $122.0 \pm 32.8^{*}$ & $164.4 \pm 6.2^{8}$ & $157.5 \pm 15.0^{8}$ \\
\hline LFA-1 & $1.2 \pm 0.5$ & ND & $1.1 \pm 0.7$ & $0.5 \pm 0.2$ & $2.6 \pm 1.0$ \\
\hline CD18 & $93.3 \pm 3.1$ & ND & $148.0 \pm 7.1^{\ddagger}$ & $118.4 \pm 7.0^{*}$ & $111.6 \pm 10.8$ \\
\hline VLA-4 & $13.0 \pm 2.6$ & ND & $13.6 \pm 1.5$ & $15.2 \pm 0.7$ & $12.7 \pm 1.3$ \\
\hline
\end{tabular}

SR, Mac-1, LFA-1, CD18, and VLA-4 expression were analyzed by flow cytometry as described in Methods. Results are expressed as net fluorescence (arbitrary units) and are the means \pm SEM of at least three samples. $N D$, not done. ${ }^{*} P<0.05,{ }^{\ddagger} P<0.01,{ }^{8} P<0.001$ versus resident macrophages. 


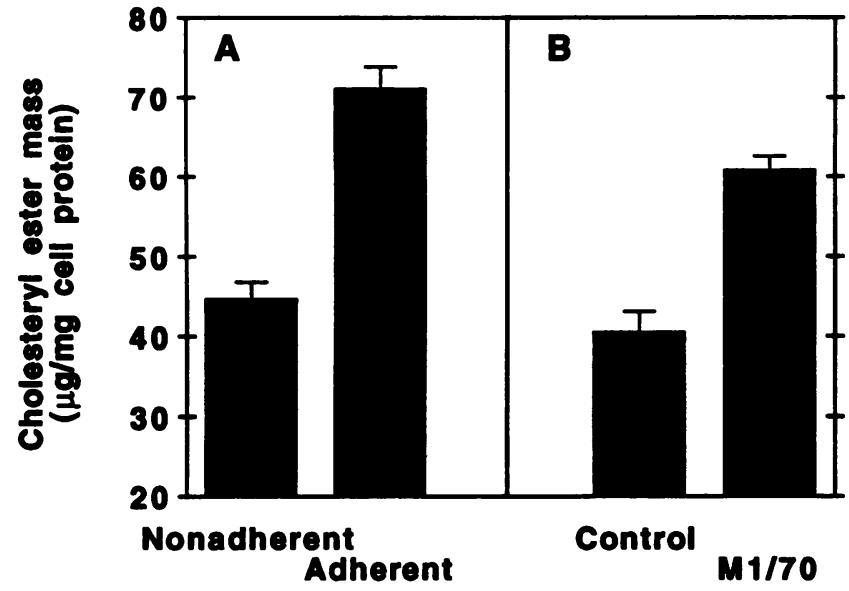

Figure 5. The effect of adherent culture $(A)$ and of Mac-1 ligation in nonadherent culture $(B)$ on CE accumulation in 24-h CP-10 $42-55$-elicited peritoneal macrophages cultured in vitro with AcLDL. Cells were incubated with AcLDL in Nunc Minisorp polypropylene tubes (nonadherent) or in polystyrene wells (adherent) for $24 \mathrm{~h}$. To ensure that cell populations for lipid extraction and analysis were equivalent in adherent and nonadherent samples, plates and tubes were centrifuged at $400 \mathrm{~g}$ for $5 \mathrm{~min}$ before and between washes with PBS before lipid extraction. Data represent the means \pm SEM of quadruplicate incubations and are representative of three experiments. In $B$, samples were preincubated with anti-Mac-1 (M1/70) or isotype control antibody in nonadherent conditions for 30 min before adding AcLDL.

purely dependent on the presence of PMNs within the inflammatory infiltrate. Moreover, populations of 24-h M-CSF-elicited (Fig. $3 \mathrm{~B}$ ) and 72-h TG-elicited cells (not shown) which had higher proportions of macrophages also failed to exhibit the enhanced AcLDL loading characteristics of CP-10 $42-55-$ recruited macrophages. Like human monocytic (42) or murine macrophage-like cell lines (43) loaded with AcLDL in vitro, the major CE fraction in AcLDL-loaded murine resident and $\mathrm{CP}-\mathbf{1 0}_{42-55}$-elicited peritoneal macrophages was cholesteryl linoleate (Table II). Compared with resident macrophages, CP$10_{42-55}$-elicited macrophages loaded both in vivo and in vitro contained proportionally less cholesteryl linoleate and more cholesteryl oleate and palmitate. Furthermore, these individual $\mathrm{CE}$ profiles were very similar to those of cells freshly isolated from human atherosclerotic plaque (Tertov, V., personal communication).

Enhanced AcLDL loading by $\mathrm{CP}-\mathbf{1 0}_{42-55}$-elicited macrophages was associated with a twofold increase in SR expression compared with resident or diluent-elicited macrophages (Table III), and its involvement in AcLDL uptake was confirmed by inhibition of CE accumulation using fucoidin. Furthermore, TGand M-CSF-elicited macrophages had levels of SR similar to those on resident cells (Table III) and did not accumulate increased CE (Fig. 3, $B$ and $C$ ). The increases in CP-10 $12_{-55}-$ elicited macrophage $S R$ expression and $C E$ accumulation in response to AcLDL were comparable with those observed in Bio-Gel-elicited macrophages cultured with M-CSF for $48 \mathrm{~h}$ (25), but less than those reported for human monocyte-derived macrophages cultured with M-CSF for $10 \mathrm{~d}$ (24). The increased SR activity reported during macrophage maturation and differentiation $(22,23)$ may contribute to the differences seen with various macrophage subpopulations and may influence potential foam cell development. In this regard, SR activity of peritoneal macrophages elicited by multiple systemic injections of M-CSF over a longer period (31) may be an interesting comparison. $\mathrm{CP}-10_{42-55}$-elicited cells harvested after $48 \mathrm{~h}$ had morphological characteristics of macrophages (increased size, vacuolar content) but loaded less efficiently in vitro even though they expressed high levels of SR. This may be due to functional differences associated with in vivo and in vitro macrophage activation (44), which may alter SR activity, affinity, and/or turnover. Furthermore, the differential expression of SR isoforms which occurs during monocyte-macrophage differentiation (23) may also be influenced by macrophage activation status and this may in turn affect macrophage AcLDL uptake. The expression of SR isoform types on macrophages harvested at various times after CP-10 $0_{42-55}$ injection would be worthy of investigation.

Expression of $\alpha_{M} \beta_{2}$ (Mac-1) was markedly increased (Table III) and that of F4/80 decreased (not shown) on monocyte/ macrophages harvested after CP-10 $0_{42-55}$, TG, and M-CSF injections, confirming them to be activated newly recruited cells (45). Expression of the $\beta$ chain (CD18) increased in parallel with Mac-1, whereas $\alpha_{L} \beta_{2}$ (LFA-1) and $\alpha_{4} \beta_{1}$ (VLA-4) levels were similar to those on resident cells. These studies confirm

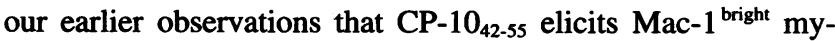
eloid cells in vivo (9), whereas it fails to directly upregulate Mac-1 expression in vitro (Cornish, C. J., J. Devery, P. Poronik, D. I. Cook, and C. L. Geczy, manuscript submitted for publication). Despite potent chemotactic activity in vivo and in vitro, the lack of a direct effect characteristic of classical chemoattractants (46) on some parameters of cellular activation is shared by other "pure", chemoattractants, e.g., TGF $\beta 1(46,47)$. The possibility that the affinity of Mac-1 may be directly altered by CP-10, as reported for other integrins (48), is currently being investigated. Our results suggest that the sustained and marked leukocyte recruitment elicited by CP-10 may be mediated by the production of other cytokines from cells within the local environment and these may contribute to and potentiate the inflammatory response.

Adhesion significantly increased macrophage CE accumulation by approximately twofold in CP-10 $0_{42-55}$-elicited (Fig. 5), resident, and TG-elicited macrophages (not shown), which were all Mac- $1^{\text {bright }}$ (Table III). Apart from contributing to the initiation of macrophage differentiation (49), which in turn is associated with increased SR activity $(22,23)$, the process of adhesion via integrin engagement may result in transduction of cellular signals that enhance leukocyte activation and effector functions $(12,13)$. Ligation of Mac-1 with a mAb which activates some functions of murine peritoneal macrophages (38) increased AcLDL loading in CP-10 ${ }_{42-55}$-elicited macrophages cultured in nonadherent conditions to a similar degree as when adherent culture was used (Fig. 5). Like the SR (20), Mac-1 can mediate both adhesion and endocytosis (14). Although MCSF-, TG-, and 48-h CP-10 ${ }_{42-55}$-elicited monocyte/macrophages were also Mac- $1^{\text {bright }}$ (Table III), levels of CEs in response to AcLDL were not significantly enhanced (Fig. 3), indicating that AcLDL uptake exclusively via Mac-1 is unlikely to be a major contributing factor to macrophage lipid loading. Optimum loading and CE accumulation may require upregulation of both SR and Mac-1 expression and/or affinity, in association with an "activated" cell status; and the process of adhesion via Mac-1 ligation may result in further cell activation or potentiation of effector functions. When monocytes are recruited to the developing atherosclerotic lesion, Mac-1 binding to its counterreceptor intercellular adhesion molecule-1 on en- 
dothelial cells (15) may initiate foam cell formation by stimulating lipid loading even before the cells transgress the endothelial barrier, especially in the setting of hypercholesterolemia.

CP-10 has $58 \%$ amino acid identity with the human $\mathrm{S} 100$ protein termed migration inhibitory factor-related protein-8 (MRP-8) (8). Like MRP-8 (50), CP-10 is expressed in bone marrow and circulating myeloid cells but not in resident tissue macrophages ( 51 ), whereas both are expressed by myeloid cells at sites of inflammation (52) (Kocher, M., personal communication). MRP-8 has been identified in human atherosclerotic plaque $(53,54)$ as part of the $\mathrm{L} 1$ antigen complex recognized by the mAb MAC 387 (55), suggesting a potential role for this or related $\mathrm{S} 100$ proteins as inflammatory mediators in this setting. CP-10 (9) and MRP-8 (56) associate with the vasculature adjacent to marginating leukocytes within inflammatory sites and are possibly secreted onto the associated endothelium as the cells diapedese. In the inflammatory and hypercholesterolemic environment of the atherosclerotic plaque, secreted CP10 may act in an autocrine or paracrine fashion which, together with other monocyte chemoattractants (e.g., monocyte chemoattractant protein-1 [5], M-CSF [4], TGF $\beta 1$ [47], and oxidized LDL [57]), may form part of the amplification mechanism required for sustained recruitment of mononuclear cells. As with any factor administered in vivo, one cannot definitively assign the observed changes in cell function to the direct action of the factor. Although it is likely that secondary mediators are responsible for some of the in vivo effects described here, CP10 or related $S 100$ proteins may have a role in stimulating leukocyte recruitment and in generating an inflammatory environment which favors macrophage lipid loading and foam cell formation in the developing atherosclerotic lesion.

\section{Acknowledgments}

We thank D. and P. Alewood for synthesizing CP-10 42 -5s; S. Gordon and W. J. S. de Villiers for their generous gift of $\mathrm{mAb} 2 \mathrm{~F} 8 ; \mathrm{K}$. E. Lovering for assistance with initial experiments; W. Jessup and L. Kritharides for helpful discussions; and C. Harrison for printing the photographs.

This work was supported by the National Health and Medical Research Council (NH\&MRC) of Australia. W. Lau holds an NH\&MRC Medical Postgraduate Research Scholarship, J. M. Devery holds an NH\&MRC Postdoctoral Award, and C. L. Geczy is a Principal Research Fellow of the NH\&MRC.

\section{References}

1. Schwartz, C. J., A. J. Valente, E. A. Sprague, J. L. Kelley, and R. M. Nerem. 1991. The pathogenesis of atherosclerosis: an overview. Clin. Cardiol. 14:I-1-I-16.

2. Gerrity, R. G. 1981. The role of the monocyte in atherogenesis. I. Transition of blood-borne monocytes into foam cells in fatty lesions. Am. J. Pathol. 103:181 190.

3. Miller, L. J., D. F. Bainton, N. Borregaard, and T. A. Springer. 1987 Stimulated mobilization of monocyte Mac-1 and p150,95 adhesion proteins from an intracellular vesicular compartment to the cell surface. J. Clin. Invest . 80:535544.

4. Wang, J. M., J. D. Griffin, A. Rambaldi, Z. G. Chen, and A. Mantovani 1988. Induction of monocyte migration by recombinant macrophage colony-stimulating factor. J. Immunol. 141:575-579.

5. Valente, A. J., M. M. Rozek, E. A. Sprague, and C. J. Schwartz. 1992 Mechanisms in intimal monocyte-macrophage recruitment. A special role for monocyte chemotactic protein-1. Circulation. 86:III-20-III-25.

6. Butcher, E. C. 1991. Leukocyte-endothelial cell recognition: three (or more) steps to specificity and diversity. Cell. 67:1033-1036.

7. Lackmann, M., C. J. Cornish, R. J. Simpson, R. L. Moritz, and C. L. Geczy.
1992. Purification and structural analysis of a murine chemotactic cytokine (CP10) with sequence homology to $\$ 100$ proteins. J. Biol. Chem. 267:7499-7504.

8. Lackmann, M., P. Rajasekariah, S. E. Iismaa, G. Jones, C. J. Cornish, S. Hu, R. J. Simpson, R. L. Moeitz, and C. L. Geczy. 1993. Identification of a chemotactic domain of the pro-inflammatory S100 protein CP-10. J. Immunol. 150:2981-2991.

9. Devery, J. M., N. J. C. King, and C. L. Geczy. 1993. Acute inflammatory activity of the S100 protein CP-10. Activation of neutrophils in vivo and in vitro. J. Immunol. 152:1888-1897.

10. Colditz, I. G., and H. Z. Movat. 1984. Kinetics of neutrophil accumulation in acute inflammatory lesions induced by chemotaxins and chemotaxinigens. $J$. Immunol. 133:2169-2173.

11. Colditz, I., R. Zwahlen, B. Dewald, and M. Baggiolini. 1989. In vivo inflammatory activity of neutrophil-activating factor, a novel chemotactic peptide derived from human monocytes. Am. J. Pathol. 134:755-760.

12. Fan, S.-T., and T. S. Edgington. 1993. Integrin regulation of leukocyte inflammatory functions. J. Immunol. 150:2972-2980.

13. Hynes, R. O. 1992. Integrins: versatility, modulation, and signaling in cell adhesion. Cell. 69:11-25.

14. Davis, G. E. 1992. The Mac-1 and p150,95 beta 2 integrins bind denatured proteins to mediate leukocyte cell-substrate adhesion. Exp. Cell Res. 200:242252.

15. van der Wal, A. C., P. K. Das, A. J. Tigges, and A. E. Becker. 1992 Adhesion molecules on the endothelium and mononuclear cells in human atherosclerotic lesions. Am. J. Pathol. 141:1427-1433.

16. O'Brien, K. D., M. D. Allen, T. O. McDonald, A. Chait, J. M. Harlan, D. Fishbein, J. McCarty, M. Ferguson, K. Hudkins, C. D. Benjamin, R. Lobb, and C. E. Alpers. 1993. Vascular cell adhesion molecule-1 is expressed in human coronary atherosclerotic plaques. J. Clin. Invest. 92:945-951.

17. Goldstein, J. L., Y. K. Ho, S. K. Basu, and M. S. Brown. 1979. Binding site on macrophages that mediates uptake and degradation of acetylated low density lipoprotein, producing massive cholesterol deposition. Proc. Natl. Acad. Sci. USA. 76:333-337.

18. Ylä-Herttuala, S., M. E. Rosenfeld, S. Parthasarathy, E. Sigal, T. Särkioja, J. L. Witztum, and D. Steinberg. 1991. Gene expression in macrophage-rich human atherosclerotic lesions. 15-lipoxygenase and acetyl low density lipoprotein receptor messenger RNA colocalize with oxidation specific lipid-protein adducts. J. Clin. Invest. 87:1146-1152.

19. Hampton, R. Y., D. T. Golenbock, M. Penman, M. Krieger, and C. R. H. Raetz. 1991. Recognition and plasma clearance of endotoxin by scavenger receptors. Nature (Lond.). 352:342-344.

20. Fraser, I., D. Hughes, and S. Gordon. 1993. Divalent cation-independent macrophage adhesion inhibited by monoclonal antibody to murine scavenger receptor. Nature (Lond.). 364:343-346.

21. Brown, M. S., and J. L. Goldstein. 1983. Lipoprotein metabolism in the macrophage: implications for cholesterol deposition in atherosclerosis. Annu. Rev. Biochem. 52:223-261.

22. Fogelman, A. M., M. E. Haberland, J. Seager, M. Hokom, and P. A. Edwards. 1981. Factors regulating the activities of the low density lipoprotein receptor and the scavenger receptor on human monocyte-macrophages. J. Lipid Res. 22:1131-1141.

23. Geng, Y.-j., T. Kodama, and G. K. Hansson. 1994. Differential expression of scavenger receptor isoforms during monocyte-macrophage differentiation and foam cell formation. Arterioscler. Thromb. 14:798-806.

24. Ishibashi, S., T. Inaba, H. Shimano, K. Harada, I. Inoue, H. Mokuno, N. Mori, T. Gatada, F. Takaku, and N. Yamada. 1990. Monocyte colony-stimulating factor enhances uptake and degradation of acetylated low density lipoproteins and cholesterol esterification in human monocyte-derived macrophages. J. Biol. Chem. 265:14109-14117.

25. de Villiers, W. J. S., I. P. Fraser, D. A. Hughes, A. G. Doyle, and S. Gordon. 1994. M-CSF selectively enhances macrophage scavenger receptor expression and function. J. Exp. Med. 180:705-709.

26. Bottalico, L. A., R. E. Wager, L. B. Agellon, R. K. Assoian, and I. Tabas. 1991. Transforming growth factor- $\beta 1$ inhibits scavenger receptor activity in THP1 human macrophages. J. Biol. Chem. 266:22866-22871.

27. Fong, L. G., A. T. Fong, and A. D. Cooper. 1990. Inhibition of mouse macrophage degradation of acetyl-low density lipoprotein by interferon- $\gamma$. J. Biol. Chem. 265:11751-11760.

28. Geng, Y.-j., and G. K. Hansson. 1992. Interferon- $\gamma$ inhibits scavenger receptor expression and foam cell formation in human monocyte-derived macrophages. J. Clin. Invest. 89:1322-1330.

29. Van Lenten, B. J., and A. M. Fogelman. 1992. Lipopolysaccharide-induced inhibition of scavenger receptor expression in human monocyte-macrophages is mediated through tumor necrosis factor- $\alpha$. J. Immunol. 148:112-116.

30. Rosenfeld, M. E., S. Ylä-Herttuala, B. A. Lipton, V. A. Ord, J. L. Witztum, and D. Steinberg. 1992. Macrophage colony-stimulating factor mRNA and protein in atherosclerotic lesions of rabbits and humans. Am. J. Pathol . 140:291-300.

31. Hume, D. A., P. Pavli, R. E. Donahue, and I. J. Fidler. 1988. The effect of human recombinant macrophage colony-stimulating factor (CSF-1) on the murine mononuclear phagocyte system in vivo. J. Immunol. 141:3405-3409. 
32. Kritharides, L., W. Jessup, J. Gifford, and R. T. Dean. 1993. A method for defining the stages of low-density lipoprotein oxidation by the separation of cholesterol- and cholesteryl ester-oxidation products using HPLC. Anal. Biochem. 213:79-89.

33. Basu, S. K., J. L. Goldstein, R. G. W. Anderson, and M. S. Brown. 1976 Degradation of cationized low density lipoprotein and regulation of cholesterol metabolism in homozygous familial hypercholesterolemia fibroblasts. Proc. Natl. Acad. Sci. USA. 73:3178-3182.

34. Brown, M. S., J. L. Goldstein, M. Krieger, Y. K. Ho, and R. G. W. Anderson. 1979. Reversible accumulation of cholesteryl esters in macrophages incubated with acetylated lipoproteins. J. Cell Biol. 82:597-613.

35. Zhang, H., H. J. K. Basra, and U. P. Steinbrecher. 1990. Effects of oxidatively modified LDL on cholesterol esterification in cultured macrophages. J. Lipid Res. 31:1361-1369.

36. Hirsch, S., J. M. Austyn, and S. Gordon. 1981. Expression of the macrophage-specific antigen F4/80 during differentiation of mouse bone marrow cells in culture. J. Exp. Med. 154:713-725.

37. Hestdal, K., F. W. Ruscetti, J. N. Ihle, S. E. W. Jacobsen, C. M. Dubois W. C. Kopp, D. L. Longo, and J. R. Keller. 1991. Characterization and regulation of RB6-8C5 antigen expression on murine bone marrow cells. J. Immunol. 147:22-28.

38. Ding, A., S. D. Wright, and C. Nathan. 1987. Activation of mouse peritoneal macrophages by monoclonal antibodies to Mac-1 (complement receptor type 3). J. Exp. Med. 165:733-749.

39. Kraemer, F. B., K. Tavangar, R. K. Gandjei, K. Kirlew, and S. R. Behr. 1990. Effects of activation on lipid and lipoprotein metabolism in murine macrophages. Arteriosclerosis. 10:8-16.

40. Khoo, J. C., E. Miller, F. Pio, D. Steinberg, and J. L. Witztum. 1992. Monoclonal antibodies against LDL further enhance macrophage uptake of LDL aggregates. Arterioscler. Thromb. 1992:1258-1266.

41. Fogelman, A. M., M. E. Haberland, and P. A. Edwards. 1984. Low-density lipoprotein receptors and scavenger receptors on monocytes and macrophagesmodulation by lymphokines. Lymphokines. 9:363-372.

42. Suzuki, K., N. Sakata, A. Kitani, M. Hara, T. Hirose, W. Hirose, K. Norioka, M. Harigai, M. Kawagoe, and H. Nakamura. 1990. Characterization of human monocytic cell line, U937, in taking up acetylated low-density lipoprotein and cholesteryl ester accumulation. A flow cytometric and HPLC study. Biochim Biophys. Acta. 1042:210-216.

43. Vercaemst, R., A. Union, and M. Rosseneu. 1989. Separation and quantitation of free cholesterol and cholesteryl esters in a macrophage cell line by highperformance liquid chromatography. J. Chromatogr. 494:43-52.
44. Adams, D. O., and T. A. Hamilton. 1984. The cell biology of macrophage activation. Annu. Rev. Immunol. 2:283-318.

45. Nibbering, P. H., J. S. Van de Gevel, and R. Van Furth. 1990. A cellELISA for the quantification of adherent murine macrophages and the surface expression of antigens. J. Immunol. Methods. 131:25-32.

46. Haines, K. A., S. L. Kolasinski, B. N. Cronstein, J. Reibman, L. I. Gold, and G. Weissmann. 1993. Chemoattraction of neutrophils by substance P and transforming growth factor- $\beta 1$ is inadequately explained by current models of lipid remodeling. J. Immunol. 151:1491-1499.

47. Allen, J. B., C. L. Manthey, A. R. Hand, K. Ohura, L. Ellingsworth, and S. M. Wahl. 1990. Rapid onset synovial inflammation and hyperplasia induced by transforming growth factor- $\beta$. J. Exp. Med. 171:231-247.

48. Carlos, T. M., and J. M. Harlan. 1994. Leukocyte-endothelial adhesion molecules. Blood. 84:2068-2101.

49. Beekhuizen, H., and R. van Furth. 1993. Monocyte adherence to human vascular endothelium. J. Leukocyte Biol. 54:363-378.

50. Lagasse, E., and I. L. Weissman. 1992. Mouse MRP8 and MRP14, two intracellular calcium-binding proteins associated with the development of the myeloid lineage. Blood. 79:1907-1915.

51. lismaa, S. E., S. Hu, M. Kocher, M. Lackmann, C. A. Harrison, S. Thliveris, and C. L. Geczy. 1993. Recombinant and cellular expression of the murine chemotactic protein, CP-10. DNA Cell Biol. 13:183-192.

52. Hessian, P. A., J. Edgeworth, and N. Hogg. 1993. MRP-8 and MRP-14, two abundant $\mathrm{Ca}^{2+}$-binding proteins of neutrophils and monocytes. J. Leukocyte Biol. 53:197-204.

53. Gordon, D., M. A. Reidy, E. P. Benditt, and S. M. Schwartz. 1990. Cell proliferation in human coronary arteries. Proc. Natl. Acad. Sci. USA. 87:46004604.

54. Arbustini, E., M. Grasso, M. Diegoli, A. Pucci, M. Bramerio, D. Ardissino, L. Angoli, S. de Servi, E. Bramucci, A. Mussini, G. Minzioni, M. Vigano, and G. Specchia. 1991. Coronary atherosclerotic plaques with and without thrombus in ischemic heart syndromes: a morphologic, immunohistochemical, and biochemical study. Am. J. Cardiol. 68:36B-50B.

55. Goebeler, M., J. Roth, S. Teigelkamp, and C. Sorg. 1994. The monoclonal antibody MAC387 detects an epitope on the calcium-binding protein MRP14. J. Leukocyte Biol. 55:259-261.

56. Hogg, N., C. Allen, and J. Edgeworth. 1989. Monoclonal antibody 5.5 reacts with p8,14, a myeloid molecule associated with some vascular endothelium. Eur. J. Immunol. 19:1053-1061.

57. Quinn, M. T., S. Parthasarathy, L. G. Fong, and D. Steinberg. 1987. Oxidatively modified low density lipoproteins: a potential role in recruitment and retention of monocyte/macrophages during atherogenesis. Proc. Natl. Acad. Sci. USA. 84:2995-2998. 